\title{
ESTUDIO HISTOLÓGICO COMPARATIVO DEL NIVEL DE PRESERVACIÓN DEL LIGAMENTO PERIODONTAL DE DIENTES AVULSIONADOS TRANSPORTADOS EN CLARA DE HUEVO Y SOLUCIÓN DE HANK
}

\author{
COMPARATIVE HISTOLOGICAL STUDY OF THE LEVEL \\ PRESERVATION OF THE PERIODONTAL LIGAMENT \\ OF AVULSIONATED TEETH TRANSPORTED IN EGG WHITE \\ AND HANKS SOLUTION
}

\author{
RITA SALCEDO RIOJA \\ Universidad Norbert Wiener \\ YOLANDA ESPEJO BARRÓN \\ Universidad Norbert Wiener \\ JHONNY VALVERDE CAMPOS \\ Universidad Norbert Wiener \\ CARLOS MICHELL GÁLVEZ RAMÍREZ \\ Universidad Norbert Wiener \\ SONIA JULIA SACSAQUISPE CONTRERAS \\ Universidad Norbert Wiener
}

\section{RESUMEN}

El objetivo del presente estudio fue comparar histológicamente el nivel de preservación del ligamento periodontal de dientes avulsionados. Se utilizaron cuatro premolares humanos sanos y fueron preservados en solución salina de Hank y en clara de huevo, previamente a ser sometidas a proceso de descalcificación con ácido nítrico al $5 \%$. Se realizaron cortes histológicos longitudinales de $4 \mu \mathrm{m}$ de espesor y fueron coloreados empleando la técnica de hematoxilina de Harris y eosina a $1 \%$. Se procedió a la lectura de las mismas bajo microscopio óptico 400x. Se observa que los tejidos periodontales preservados en solución de Hank y en clara de huevo tienen características similares; sin embargo, se requiere mayores estudios.

Palabras clave: clara de huevo, solución de Hank, avulsión permanente.

\section{ABSTRACT}

The objective of this research was compared histologically the level of preservation of the periodontal ligament of avulsed teeth. Four healthy human premolars were used and were preserved in Hank's saline solution and egg white, before being submitted to a process of decalcification with $5 \%$ nitric acid. Longitudinal histological sections of $4 \mu \mathrm{m}$ thickness were made and colored using the Harris haematoxylin-eosin $1 \%$ technique. They were read under a $400 \mathrm{x}$ optical microscope. It is observed that the periodontal tissues preserved in Hank's solution and in egg white have similar characteristics; however, further studies are required.

Key words: Hanks Balanced Salt Solution, Tooth avulsion, Egg white. 


\section{INTRODUCCIÓN}

Los traumatismos dentoalveolares, $y$ en particular la avulsión dentaria, son situaciones de emergencia que se producen como consecuencia de un impacto violento en la cavidad bucal y necesitan tratamiento inmediato. Los grupos de mayor riesgo son los niños y jóvenes, quienes, por el tipo de actividades que realizan y el proceso de desarrollo emocional en el que se encuentran, junto con los componentes locales personales, son más vulnerables a sufrir este tipo de accidentes. Cabe resaltar también que si se trata de dientes deciduos, no se debe realizar la reposición por el riesgo de dañar al germen sucedáneo ${ }^{1}$.

El protocolo de acción ante una avulsión dentaria de un diente permanente es la reposición inmediata ${ }^{1,2}$. Por otro lado se ha demostrado que cuando el tejido periodontal ha sido preservado adecuadamente en el transporte de la pieza avulsionada el pronóstico de permanencia de la pieza en boca es mejor, por esta razón se han estudiado diversos tipos de sustancias ${ }^{3,4.5}$ que podrían tenerse a la mano en el momento del accidente como la leche, bebidas rehidratantes, líquidos de limpieza de lentes de contacto, suero fisiológico, clara de huevo, etcétera. En países desarrollados existe un protocolo de acción cuando ocurre este tipo de accidentes, que incluye un paquete llamado Save a tooth, que es un frasco adecuado para el transporte del diente con la solución balanceada de Hank ${ }^{6}$.

Ni la leche descremada ni la solución de Hank son fáciles de obtener en ubicaciones rurales de nuestro país, por lo que una opción más asequible en estas zonas sería la clara de huevo 7 .

\section{MÉTODO}

Se seleccionaron cuatro premolares sanas indicadas para exodoncia, extraídas con el mismo protocolo para todas; una de ellas para el control negativo, la que luego de ser extraída fue mantenida por una hora sobre una toalla de papel a la intemperie; la segunda fue procesada inmediatamente de ser extraída, la que sería el control positivo. Las piezas experimentales fueron sumergidas en clara de huevo y solución de Hank, por una hora. El proceso de cada una de las piezas dentales fue el siguiente: fueron sumergidas en formol al $10 \%$, luego se les descalcificó con ácido nítrico al $5 \%$. Se realizaron cortes histológicos longitudinales de $4 \mu \mathrm{m}$ de espesor y fueron coloreados empleando la técnica de hematoxilina de Harris y eosina a $1 \%$.

La observación con microscopio óptico 400X mostró los siguientes resultados:

Se observa al tejido periodontal con fibras de colágeno desorganizadas, escasos fibroblastos y focos de necrosis (Figura 1).

Se observa gran cantidad de fibroblastos y fibras de colágeno organizadas; se observan focos de necrosis (Figura 2).

Se observa gran cantidad de fibroblastos, fibras de colágeno sin organización, células inflamatorias, escasos focos de necrosis (Figura 3).

Se observa escasos fibroblastos, fibras de colágeno sin organización y focos de necrosis (Figura 4).

Las características histológicas del ligamento periodontal son similares en ambas sustancias de transporte, aunque 
se podría calificar con mejores características de viabilidad al ligamento preservado en solución de Hank.

\section{DISCUSIÓN}

Existen numerosas investigaciones sobre la preservación del tejido periodontal en casos de avulsión, la mayoría de ellos enmarcados en estudios in vitro porque los estudios clínicos no son viables. Luego de observar el resultado de este estudio preliminar estamos de acuerdo con Granger et al. ${ }^{8}$, quienes se hicieron una pregunta importante: ¿vale la pena el reimplante del diente avulsionado? Luego de una búsqueda bibliográfica sistemá-

\section{FIGURA 1}

Control negativo: Microfotografía de ligamento periodontal (hematoxilina-eosina 400X)

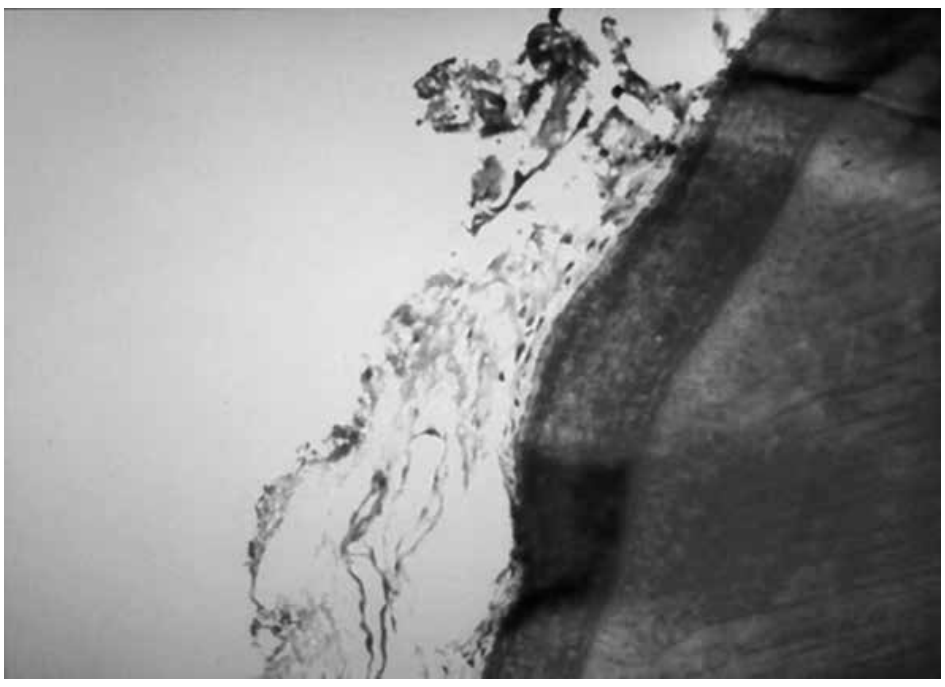

\section{FIGURA 2}

Control positivo: Microfotografía de ligamento periodontal (hematoxilina-eosina $400 \mathrm{X}$ )

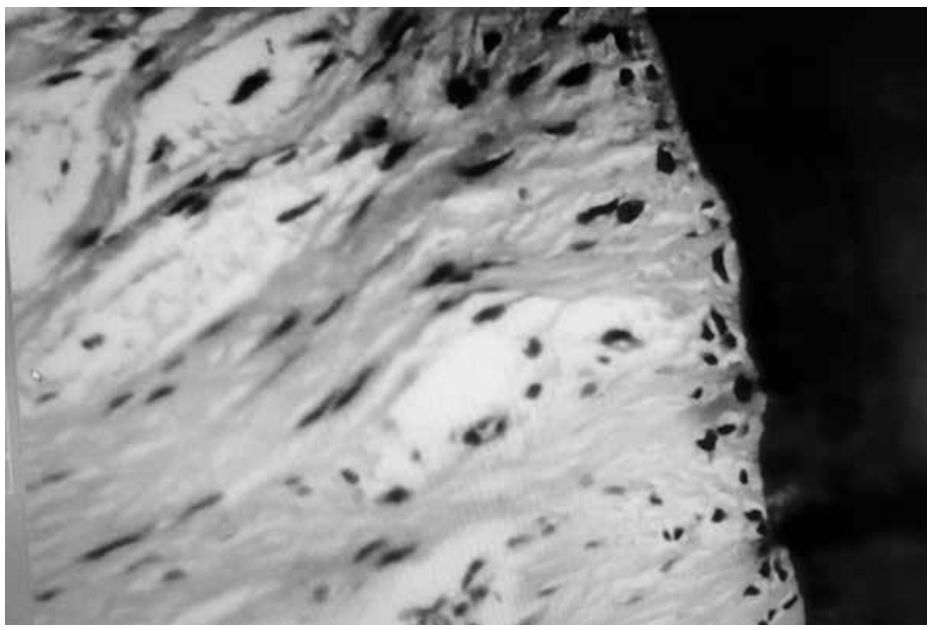




\section{FIGURA 3}

Solución de Hank: Microfotografía de ligamento periodontal (hematoxilina-eosina $400 \mathrm{X}$ )

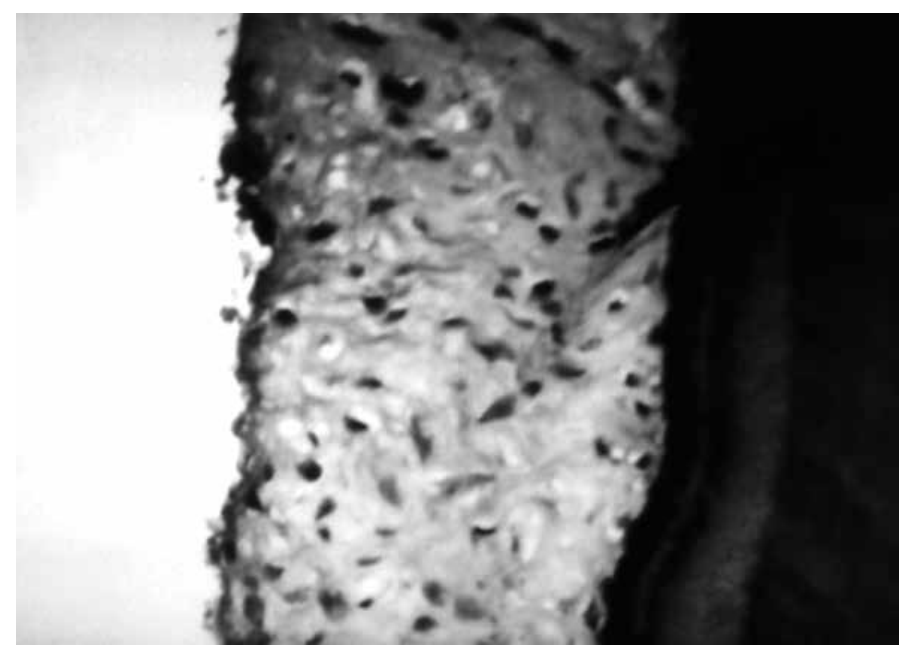

FIGURA 4

Clara de huevo: Microfotografía de ligamento periodontal (hematoxilina-eosina 400X)

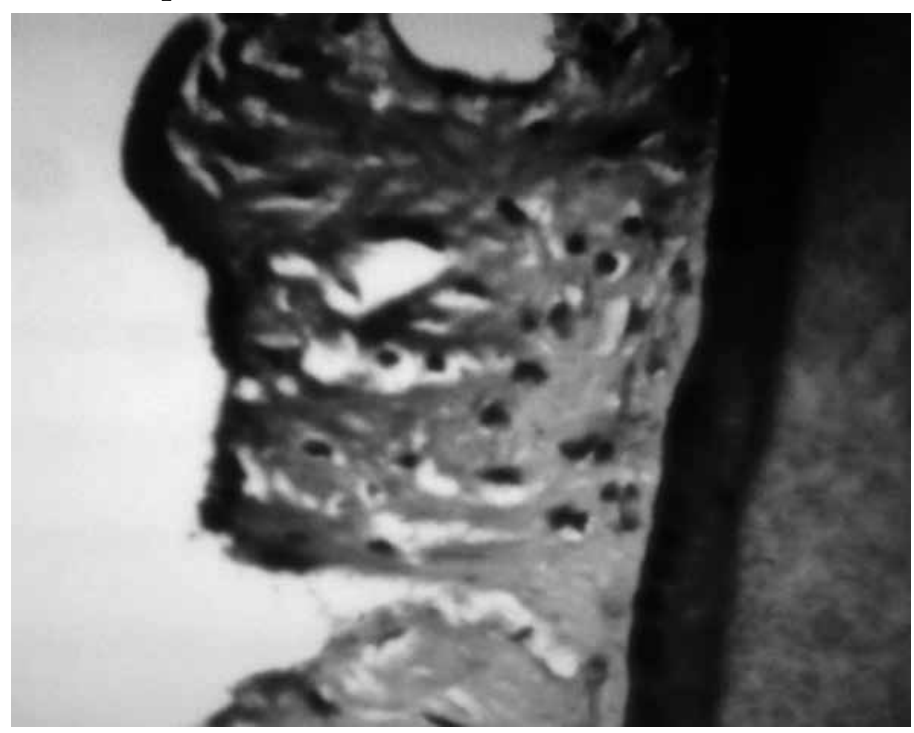

tica, llegaron a la conclusión de que, en efecto, es necesaria, pero faltan más estudios para determinar la existencia de un medio ideal.

En 2015, Sharma et al. ${ }^{9}$ estudiaron tres líquidos como medios de transpor- te: leche, clara de huevo y aloe vera; encontraron que el aloe vera es más eficiente en la preservación de las células que la leche y el huevo. La diferencia sustancial con el presente estudio es que fueron realizados cultivos celulares para observar la viabilidad de las células, lue- 
go de permanecer en los diferentes medios de transporte.

Goswami $^{10}$, Wang ${ }^{11}$, Moura ${ }^{12}$, Hwang ${ }^{13}$ y Mousavi ${ }^{14}$ estudiaron diferentes medios de transporte para dientes avulsionados: leche descremada, té verde, bebidas rehidratantes, con resultados histológicos diversos en la preservación del tejido periodontal. Ninguno de ellos considera a la clara de huevo como una sustancia óptima como medio de transporte del diente avulsionado, pero están de acuerdo en que la solución de Hank es el más adecuado.

Partovi $^{15}$ y Ashkenazi ${ }^{16}$ realizaron estudios específicos sobre los fibroblastos del periodonto, aunque con resultados que no son comparables entre sí. Alientan a seguir investigando en la búsqueda de soluciones alternativas viables y disponibles en el momento del accidente.

En el Perú existen dos estudios importantes sobre el tema. Rodriguez ${ }^{17}$ comparó histológicamente la leche descremada y la clara de huevo: su conclusión es que la clara de huevo es una muy buena opción cuando no existe leche descremada disponible. Lauracio ${ }^{18}$ comparó la leche evaporada, clara de huevo y agua de coco desde el punto de vista de la viabilidad de las células periodontales, llegando a la conclusión de que son similares.

\section{CONCLUSIÓN}

El estudio histológico cualitativo preliminar realizado nos permite concluir que los tejidos periodontales preservados en clara de huevo y solución de Hank tienen características similares; sin embargo, se requiere mayores estudios con seguimiento.

\section{REFERENCIAS BIBLIOGRÁFICAS}

1. Flores MT, Andersson L, Andreasen J, Bakland L, Malmgren B, Barnett F, Bourguignon C, DiAngelis A, Hicks L, Sigurdsson A, Trope M, Tsukiboshi M, Von Arx T. Guidelines for the management of traumatic dental injuries. II. Avulsion of permanent teeth. Dental Traumatology, 23: 130-136. 2007.

2. Abdullah D, Liew A, Wan Noorina W, Khoo $S$, Wee F. Association of dental trauma experience and first-aid knowledge among rugby players in Malaysia. Dent Traumatol, 31: 403-408. 2015.

3. Bharath MJ, Sahadev CK, Ramachandra PKM, Rudranaik S, George J, Thomas A. Comparative evaluation of four transport media for maintaining cell viability in transportation of an avulsed tooth An in vitro study. Journal of International Society of Preventive \& Community Dentistry, 5(1), 69-73. 2015.

4. Moura CCG, Soares, PBF, de Paula Reis MV, Fernandes Neto AJ, Zanetta Barbosa D, Soares C. Potential of coconut water and soy milk for use as storage media to preserve the viability of periodontal ligament cells: an in vitro study. Dent Traumatol, 30: 22-26. 2014.

5. Poi WR, Sonoda CK, Martins CM, Melo ME, Pellizzer E, De Mendonça MR et al. Storage Media For Avulsed Teeth: A Literature Review. Braz. Dent. J. 24(5): 437-445. 2013.

6. Lee W. Viability of Human Periodontal Ligament Fibroblasts After Storage in Save-A-Tooth, EMT Toothsaver and Hank's Balanced Salt Solution Master's Theses2009. Consulta: 27 diciembre de 2016. Disponible en: http://epublications.marquette.edu/theses_open/362/

7. Análisis del mercado mundial del huevo y ovoproductos. Consulta: 27 diciembre de 2016. Disponible en: http:// 
www.elsitioavicola.com/articles/2044/ analisis-del-mercado-mundial-del-huevo-y-ovoproductos/

8. Granger T, Gunn A, Welbury R. Tooth replantation: a worthwhile exercise?. Acta Stomatologica Croatica [serial on the Internet]. (2011, June), [cited May 16, 2016]; 45(2): 75-84. Available from: Dentistry \& Oral Sciences Source.

9. Sharma M, Sharma S, Reddy Y, Mittal R, Agarwal V, Singh A, et al. Evaluation of Periodontal Ligament Cell Viability in Three Different Storage Media: An in Vitro Study. Journal Of Dentistry Of Tehran University Of Medical Sciences [serial on the Internet]. (2015, July), [cited May 16, 2016]; 12(7): 524531. Available from: Dentistry \& Oral Sciences Source

10. Goswami M, Chaitra T, Chaudhary S, Manuja N, Sinha A. Strategies for periodontal ligament cell viability: An overview. Journal Of Conservative Dentistry [serial on the Internet]. (2011, July), [cited May 16, 2016]; 14(3): 215-220. Available from: Dentistry \& Oral Sciences Source.

11. Wang W, Zhao Y, Feng X, Jia W, Ge L. Effect of skimmed pasteurized milk and Hank's balanced salt solution on viability and osteogenic differentiation of human periodontal ligament stem cells. Dental Traumatology [serial on the Internet]. (2013, Oct), [cited May 16, 2016]; 29(5): 365-371. Available from: Dentistry \& Oral Sciences Source.

12. Moura C, Soares P, Reis P, Fernandes Neto A, Zanetta Barbosa D, Soares C. Potential of coconut water and soy milk for use as storage media to preserve the viability of periodontal ligament cells: an invitro study. Dental Traumatology [serial on the Internet]. (2014, Feb),[cited May 16, 2016]; 30(1): 22-26. Available from: Dentistry \& Oral Sciences Source.
13. Hwang J, Choi S, Park J, Kang S. The Use of Green Tea Extract as a Storage Medium for the Avulsed Tooth. Journal Of Endodontics [serial on the Internet]. (2011, July), [cited May 16, 2016]; 37(7): 962-967. Available from: Dentistry \& Oral Sciences Source.

14. Mousavi B, Alavi S, Mohajeri M, Mirkheshti N, Ghassami F. Standard Oral Rehydration Solution as a new storage medium for avulsed teeth. International Dental Journal [serial on the Internet]. (2010, Dec),[cited May 16, 2016]; 60(6): 379-382. Available from: Dentistry \& Oral Sciences Source.

15. Partovi M, Sadeghein A, Azizi E, Ostad S. Mitogenic Effect of 1-dopa on Human Periodontal Ligament Fibroblast Cells. Journal Of Endodontics [serial on the Internet]. (2002, Mar), [cited May 16, 2016]; 28(3):193-196. Available from: Dentistry \& Oral Sciences Source.

16. Ashkenazi M, Marouni M, Sarnat H. In vitro viability, mitogenicity and clonogenic capacities of periodontal ligament fibroblasts after storage in four media supplemented with growth factors. Dental Traumatology [serial on the Internet]. (2001, Feb), [cited May 16, 2016]; 17(1):27-35. Available from: Dentistry \& Oral Sciences Source.

17. Rodriguez K. Comparación histológica de ligamento periodontal humano preservado en clara de huevo y leche descremada, Tesis bachiller Odontología UNMSM 2014. Consulta: 20 de mayo de 2016. Disponible en: <http://cybertesis.unmsm.edu.pe/handle/cybertesis/3654>.

18. Lauracio C, Chayña E, Ramos W, Padilla T, Catacora P. Viabilidad de la células del Ligamento Periodontal en Diferentes Medios de Almacenamiento y Transporte, Kiru 10(2)91-95 2013. Consulta 26 de mayo 2016. Disponible en: <http://www. usmp.edu.pe/odonto/servicio/2013/Kiruv.10.2/Kiru_v.10.2_Art.1.pdfs. 